\author{
Review Essay
}

\title{
Documentation Status Socialization as an Ethnic-racial Socialization Dimension: Incorporating the Experience of Mixed-status Latinx Families
}

\author{
FERNANDA LIMA CROSS
}

University of Michigan, USA

\begin{abstract}
Ethnic-racial socialization (ERS) serves as a protective factor in the development of minority children. However, few studies have focused on mixed-status Latinx families to include the broad expression of their ethnic-racial socialization practices centering on their immigration experiences as they teach their children the risks and restrictions of having undocumented status. These parents adapt their ERS in accordance with their experiences of stress, fear, and discrimination, all of which shape the type and frequency of their socialization messages. Through documentation status socialization, Latinx parents forewarn their children of the inequities associated with their ethnic-racial group and undocumented status, including possible family separation. They also teach children about nativity differences and the attendant privilege of having documented status. This manuscript highlights insights to be gained by considering documentation status socialization as an ERS dimension within Latinx families. Learning about the specific ERS practices of such an understudied group is a social justice issue with important implications for understanding how these families might adapt and respond to their social context, especially amidst a political environment that engenders fear and isolation throughout their community. Including documentation status socialization in the ERS literature is a crucial step towards developing a deeper understanding of how the structural and social forces operating within the lives of undocumented immigrants impact normative family processes that ultimately exert an influence on their children's development. A discussion on implications for practitioners and service providers working with this population is also included.
\end{abstract}

KEYWORDS ethnic-racial socialization; undocumented immigrants; documentation status socialization 
There are about 10.4 million undocumented immigrants residing in the United States, the large majority of whom are of Latin American origin (Warren, 2021). They are raising an estimated 4.5 million children who, by virtue of birth here, possess American citizenship (Zayas \& Gulbas, 2017). Besides citizen children, some of these undocumented parents have undocumented children brought to this country at a very young age, who were raised here and likely feel as American as citizen children do (Zayas, 2015). These immigrants face inequalities beyond that of their racial and economic status. Their undocumented status overrides other social forces and becomes part of their identity, thereby shaping their daily lives, influencing how they are perceived and treated by others, and limiting their opportunities. Most aspects of their lives are negatively impacted by their lack of authorization to be present in this country (Gleeson \& Gonzales, 2012). Given the myriad ways undocumented status affects these parents, it is likely to inform what they teach their children about race and ethnicity as well.

Parents dealing with documentation status issues face the dread of being identified as undocumented and consequently having their families torn apart by deportation. Children aware of the undocumented status of their parents live with the ever-present threat of separation due to deportation. These parents may accordingly adapt their socialization practices due to fears of being exposed and to prepare their children for the possible outcomes associated with being undocumented (Ayón, 2016). Sharing with their children the fragility of the family's situation often leads to difficult conversations at home, which constitute ethnic-racial socialization (ERS) messages peculiar to mixed-status families (Suárez-Orozco et al., 2011).

ERS includes the ways in which parents teach their children about their ethnic-racial group with the goals of helping them develop feelings of pride in their culture and connections to their heritage as well as to prepare the youth to face discrimination and navigate an oppressive society (Hughes et al., 2006; Huguley et al., 2019). Examination of these socialization efforts helps us understand how minority parents react to social inequalities, prejudice and discrimination, as well as how they prepare their children to confront these same issues (Ayón, 2016; Hughes et al., 2006). As a step towards promoting the consideration of a broader spectrum of experiences of Latinx immigrant families, this manuscript argues for regarding documentation status socialization as an ERS dimension. Documentation status socialization not only teaches children the risks and restrictions imposed by undocumented status, but also provides them with some measure of agency over their situation through learning about the plans their parents have laid to ensure the family's safety and reunification in case of separation. It also teaches children about their own nativity and documentation status, and rights that the youth are entitled to as U.S citizens. These parental teachings might also serve to counteract children's negative feelings associated with belonging to an immigrant family and foster family union (Ayón, 2016; Cross et al., 2020). Acknowledging documentation status socialization as an important ERS 
dimension (especially to Latinx immigrant families) will expand the ERS literature by improving our understanding of what and how parents have been communicating to their children regarding the impact of undocumented status on their family and community (Ayón, 2018; Cardoso et al., 2018; García, 2019). In this article, I build on the existing ERS literature to underscore the ways in which the experiences of undocumented Latinx parents could be more fully explored to incorporate the broad expression of their ERS practices, including their documentation status socialization. Drawing from the Integrative Model (Garcia Coll et al., 1996; Stein et al., 2016) I explain the impact of parental foreign and undocumented status on their ERS. I offer examples of how documentation status socialization has likely always been part of the ERS of Latinx immigrant families and I discuss some of the sociocultural contextual factors impacting the need for such socialization, especially over the last few decades. Finally, I conclude offering potential suggestions for future research and strategies for practice so service providers working with this population can better serve them.

\section{The Ethnic-racial Socialization of Latinx Families}

ERS has been found to encompass a set of protective and adaptive practices employed by parents to promote their children's development. However, this process is of particular importance to ethnic minority parents as they share with their children their heritage and cultural history, transmit their views and perceptions about race and ethnicity and prepare them for the world beyond their home (Hughes et al., 2006). In contemporary research, the process is no longer viewed as a unidimensional construct, but rather composed of several major themes or dimensions that have emerged from studies regarding ERS messages, beliefs, and practices. These themes represent different aspects of socialization that parents engage in as reported by parents themselves or by their adolescent children (Hughes et al., 2009).

Latinx parents transmit cultural values to their children, teaching them history, customs, traditions, and ethnic heritage to promote the development of racial or ethnic pride. Such cultural socialization has been identified as one of the principal ERS dimensions employed by this group. To accomplish this, parents use native language in the home, celebrate cultural holidays, and teach children about their heritage through books, music, and food (Ayón et al., 2018; Umaña-Taylor et al., 2009). Another common socialization method used by Latinx parents is preparation for bias, in order to teach their children about discrimination and prepare them to deal with it. These messages regarding intergroup relations are less common than cultural socialization messages, possibly due to parental discomfort with the negative feelings prompted by addressing the topic of discrimination (Espinoza et al., 2016; Hughes, 2003). Parents also hesitate to raise the topic of prejudice with their children for fear that it might negatively influence their self-esteem and ethnic 
affect (Hughes et al., 2006). Promotion of mistrust messages focus on lack of trust regarding other ethnic groups and warnings about intergroup interactions (Grindal \& Nieri, 2015; Hughes et al., 2006). The difference between preparation for bias and the less common promotion of mistrust is that the latter emphasizes distrust without offering any suggestions on how to handle encounters with discrimination.

In a mixed-methods study with Latinx immigrant families (Cross et al., 2020) undocumented parents were found to employ the varied dimensions of ERS differently than documented ones. Quantitative analysis indicated that undocumented parents transmitted more cultural socialization messages than those of documented status. The undocumented participants' inability to visit their native country curtails their children's option of direct cultural exposure, thus intensifying the importance of and need for cultural transmission at home. These parents were also more likely to teach them to be wary of interactions with law enforcement personnel and non-Latinxs. In addition, interview results highlighted the importance placed by both groups in preparing their children for discrimination. However, undocumented parents tended to encourage their children to disregard encounters with discrimination and not engage with the perpetrators, while documented parents instructed their children to stand up for themselves and their families. Such results highlight variances in ERS according to documentation status and demonstrate the need for continued study of the different aspects of Latinx immigrants' socialization practices, including the reasoning and motivation behind them (author citation). In sum, my work builds upon the widely studied dimensions of ERS to better capture the experiences of Latinx immigrants, especially those of undocumented status.

\section{ERS and Children's Outcomes}

Children exposed to ERS are shown to exhibit numerous beneficial outcomes, including positive ethnic identity development, increased engagement with school, and improved mental health (e.g., Constante et al., 2019; McDermott et al., 2018). In a longitudinal study with 323 Latinx youth, Douglass and Umaña-Taylor (2016) demonstrated the positive influence of cultural socialization across adolescence with ethnic identity exploration becoming stronger as the children aged. The protective benefits associated with teaching children about their parents' native culture have also been associated with improved academic outcomes. In a sample of 321 Latinx adolescents, cultural teachings fostered the development of coping strategies against discrimination and were related to higher GPA (McDermott et al., 2018). Similarly, Berkel et al. (2010) found that cultural socialization helped children feel positively about their ethnicity by engendering a deep sense of connection to their heritage, which in turn was associated with improved mental health and academic self-efficacy, even in the face of high levels of 
discrimination.

Parental messages preparing children to face discrimination have also been found to play an important role in their lives as they encounter discrimination. In a study with 175 Latinx middle schoolers in an emerging immigrant community, Kulish et al. (2019) found that those exposed to preparation for bias messages were more likely to develop greater awareness of discrimination. These messages have also been associated with lower selfesteem among Latinx adolescents (Espinoza et al., 2016). In addition, Espinoza et al. (2016) found that transmitting mistrust of other ethnic-racial groups has been associated with greater internalizing and externalizing problems among the youth. These parental messages aimed at protecting their children by preparing them for future maltreatment have been explored longitudinally using a sample of 251 Mexican-origin adolescents. Over time, fathers' promotion of mistrust was found to intensify the deleterious effect of adolescents' perception of discrimination on their depressive symptoms (Park et al., 2019).

While this literature has addressed the general experience of Latinxs in the United States, there has been a dearth of research focusing on families of undocumented or mixed immigration status (where some or all of the children are American citizens and one or more of the parents are undocumented; Ayón et al., 2020). ERS messages are shaped by the various social stratification factors that permeate the lives of immigrants, including discrimination, oppression, socioeconomic status, level of education, age, gender, parental attitudes and experiences, generation of immigration, and documentation status. Thus, it could be expected that undocumented parents adapt their ERS practices to reflect the constrained realities of their status as it exposes them to more pervasive and explicit ethnic discrimination in their everyday lives, a well acknowledged influence on ERS (Ayón, 2016; Hughes et al., 2006).

\section{Theoretical Framework}

When considering the influence of parents' documentation status on their ERS practices, the Integrative Model is a useful framework providing links among social position, discrimination, and family processes (García Coll et al., 1996). Social position in the Integrative Model refers to how society ranks people within a social hierarchy based on their race, ethnicity, gender and economic level. Previous work revising the Integrative Model proposed undocumented status as a relevant social position variable for Latinxs living in rural and new immigrant destination areas, along with foreigner status and migrant farmworker status (Stein et al., 2016). Latinx immigrants occupy a lower position in the social hierarchy due to perceptions of foreignness when compared to immigrants racialized as White (Finch et al., 2001). Furthermore, undocumented Latinx immigrants fall even lower in this hierarchy due to the 
negative compounding effects of being immigrants, members of an ethnic or racial minority, and undocumented. The high levels of discrimination and oppression these immigrants experience pervade many aspects of their lives, by restricting their work and income prospects, their access to medical care and good schooling for their children, the neighborhoods they can live in, and consequently the people they interact with (Suárez-Orozco et al., 2011). When considered in the family context, these pervasive factors exert influence on the ERS messages transmitted at home. This is especially true for recently arrived immigrant families settling in new immigrant destinations, where the lack of cultural resources and community support to help them navigate their new environments and manage discrimination also impacts the messages parents share with their children regarding race and ethnicity (Stein et al., 2016).

\section{The Socio-political Context and ERS of Undocumented Immigrants}

While it is undeniable that most undocumented immigrants in the US experience fear and stress in their daily lives, Latinxs endure even greater levels because of ethnic-racial profiling. Latinxs have suffered the brunt of deportations, with almost all of those deported between 1997 and 2012 being Latin American (Golash-Boza \& Hondagneu-Sotelo, 2013). More recently, Mexicans represented 70\% of those deported in 2015 (Transactional Records Access Clearinghouse, 2016). Such targeted enforcement demonstrates a historical racialization of undocumented immigration as a Latinx issue, portraying scary brown criminals crossing our border and taking over the jobs of American citizens (Chavez, 2013). This Latinx threat narrative has been accompanied by increases in proposed anti-immigrant legislation, stricter enforcement policies, and heightened negative media portrayal (Massey \& Pren, 2012). Arizona and Texas, for example, have had long histories of adopting and enforcing laws that rely heavily on ethnic-racial profiling of Latinxs aimed at curtailing undocumented immigrants' access to resources or opportunities. These policies and practices restrict immigrants' employment and educational prospects and allow law enforcement personnel to be blatantly discriminatory by asking to see the "papers" of those they suspect of being undocumented, all of which contribute to a heightened perception of discrimination among Latinxs (Ayón \& Garcia, 2019; FitzGerald et al., 2019).

Many recent immigrants from Latin America are low-skilled hard-working migrant laborers, most of whom are undocumented. Their lack of documentation is among the principal reasons they are targets of discrimination and excluded socially (Flippen \& Parrado, 2015). These immigrants who arrive in the US to face critical portrayals of their ethnicracial group and experience negative interactions with others will accordingly adapt their beliefs and parenting practices in response (García Coll et al., 
1996; Suárez-Orozco et al., 2011). It is in this hostile environment that undocumented Latinxs have been raising their children and preparing them to face the realities associated with belonging to a disenfranchised ethnic-racial group.

Not surprisingly, conversations regarding documentation status issues and its associated vulnerabilities have been found to take place between undocumented parents and their children. When a parent is deported, children often experience psychological trauma, develop poor physical and mental health, display aggressive behaviors, and endure economic hardship (Chaudry et al., 2010). Should both parents get deported, in the absence of documented relatives willing to care for the children, they are placed in foster care. In extreme cases, families become permanently separated as parents lose custody of or contact with their children. If reunification does occur, it usually takes years (Amuedo-Dorantes \& Arenas-Arroyo, 2018; Hall, 2011).

Citizen children of deported or detained undocumented parents have been found to display greater psychological distress and PTSD symptoms than those whose parents have had no contact with immigration authorities (RojasFlores et al., 2017). A study of 2,500 Latinx children demonstrated that those with undocumented parents exhibited higher levels of internalizing and externalizing behavior issues than Latinx children of documented or citizen parents (Landale et al., 2015).

The children of undocumented immigrants do not need to have actually experienced the deportation of a parent to become aware of its disastrous consequences through classmates, neighbors, and TV (Capps et al., 2007). Merely knowing someone who has been deported is associated with increased need for mental health support, regardless of one's own documentation status (Vargas et al., 2019). This awareness often causes children of immigrants to perceive their immigrant heritage negatively, to associate "immigrant" with "illegality," and to want to distance themselves from their background (Dreby, 2012). The more the parents are at risk for deportation, the more stressed are the children (Brabeck \& Xu, 2010). For instance, young US citizen children of undocumented immigrants report experiencing higher levels of anxiety when compared to children of documented parents (Brabeck $\&$ Sibley, 2016). This constant threat of deportation affects the large majority of children of undocumented immigrants by pervading their lives with a constant fear of abandonment and family dissolution (De Genova, 2010), thereby inhibiting their healthy development (Suárez-Orozco et al., 2011).

The process by which parents share information with their children regarding parental documentation status and its related inequities constitutes an important ERS dimension for Latinx immigrants. Exploring this in mixedstatus families, utilizing culturally relevant measures, may well provide the field with critical information regarding how such socialization impacts children's development. 


\section{Documentation Status Socialization}

In light of the stricter immigration enforcement adopted by the US in the past few years, it might be expected that undocumented Latinx parents are engaging in unprecedented levels of documentation status socialization (Heinrich, 2018). It is worth noting that while researchers have only recently started considering the varied range of ERS among Latinxs immigrant families, documentation status socialization has likely always been an essential part of the ERS arsenal of these families.

Through documentation status socialization, Latinx parents teach their children about not only the inequities experienced by members of their ethnic group but also the ways in which the family has prepared to handle these challenges (Lykes et al., 2013; Cross et al., 2021). The desire to shield children from an uncertain future is reflected in these parents' ERS, which differs from that of parents not at risk for deportation. Some undocumented parents, wishing to guard their children from the consequences of these uncertainties, may strongly encourage them to assimilate into mainstream society (Suárez-Orozco et al., 2011). In addition, children are often given explicit rules about not drawing attention to themselves or their family, since such attention could jeopardize their family's future by way of a parent's deportation (Zayas, 2015).

Documentation status socialization also encompasses teaching children about the overall vulnerability and injustice associated with having undocumented status, coaching them to behave so as to reduce their chances of being identified as undocumented, and explaining the benefits afforded to the documented, which include the privilege of having documented status or being an American citizen. They also discuss the risk of parental deportation, and, for the undocumented children, the risk of their own deportation, as well as contingency plans in case of detainment or deportation. In a study conducted with Latinx immigrants living in the Midwest, documentation status socialization was reportedly part of the ERS of both documented and undocumented parents. This socialization also included parents helping their children view border crossing as necessary for survival and not always a choice (Cross et al., 2021). In addition, in a review of the ERS literature of Latinx families, Ayón et al. (2020) highlighted a study in which Latinx immigrant parents reported teaching their children differences in the birthplace and documentation status of members of the same family.

Not enough studies with this population have been conducted to provide more in-depth information about when and why parents decide to engage in documentation status socialization with their children. Many parents choose not to share their contingency plans with their children or initiate these conversations with them. They report not knowing how to talk about the risk of deportation and family separation with their children and not wanting to worry them about it (Balderas et al., 2016). In a study with 132 Latinx immigrants, less than half of the sample reported engaging in these 
conversations with their children even though they acknowledged the need for these discussions (Lykes et al., 2013). Similarly, about $25 \%$ of the undocumented parents interviewed by Cardoso et al. (2018) reported not talking about documentation status issues with their children. García (2019) reported that parents consider their children's age and ability to grasp certain concepts in their decisions to talk to them about documentation status, many opting for silence or for sharing only the most basic information with their younger children.

However, oftentimes parents do not have the choice of shielding their youngsters from these difficult and emotional conversations. For example, immigrants interviewed by Balderas et al. (2016) reported engaging in documentation status socialization in response to children's questioning after being exposed to the topic elsewhere. Children also have been found to raise these topics with parents in response to their own encounters with discrimination, witnessing raids in their neighborhood, or hearing stories in the media, which indicates their awareness of the prejudice and antiimmigrant sentiments impacting their community. In addition, when faced with the detainment or deportation of a close family member, parents are forced to break the silence and teach their children about these issues.

This dimension of ERS reflects the overall Latinx immigrant experience in the US and is heavily influenced by the socio-context of the families and overall political climate of the country. Cognizant of this, Ayón (2018) developed a new ERS measure drawing from in-depth interviews with Latinx immigrants (Ayón, 2016) and validated through a survey with 300 Latinx parents (Ayón, 2018), which indicated that conversations regarding nativity and documentation status were part of their ERS repertoire. Continued examinations of documentation status socialization have potential implications for the socio-emotional and socio-political development of their children, as they come to comprehend the racialized nature of undocumented immigration, the targeted enforcement of Latinxs, and the inherent social inequalities associated with being part of a Latinx immigrant family (Anyiwo et al., 2018; Pinetta et al., 2020; Suárez-Orozco \& Yoshikawa, 2013). As these children mature, they become increasingly aware - through stories in the media and conversations at home - of the continuous threat of deportation that many members of their ethnic group face here in the United States. This perception could influence their view of and feelings towards their ethnic group (Dreby, 2012). Realization of both the vulnerability of their family's future and of belonging to a marginalized group is known to affect children's psychosocial development (Suárez-Orozco et al., 2011).

However, most ERS studies have not specifically focused on mixed-status families, which has precluded the examination of the possible role of parents' undocumented status on their socialization processes. Consideration of parental documentation status could help disentangle some of the associations between ERS and youth outcomes, as well as shed light on additional strategies these parents use to socialize their children. For example, findings 
from a mixed-method examination comparing and contrasting the experiences and family practices of documented and undocumented Latinx immigrants revealed that undocumented parents transmitted more promotion of mistrust messages to their adolescents than parents of documented status. These mistrust messages were, in turn, related to higher levels of depressive symptoms among those adolescents (Cross et al., 2020). Such higher use of promotion of mistrust among the undocumented reflect their current reality of living with the constant threat of deportation, prompting parents to warn their adolescents of interactions with people of other ethnic groups in order to protect their family. That study, one of the first to focus directly on the ERS of mixed-status families, sheds light on the differential impact of parental undocumented status on their family processes and their adolescents' outcomes. It also argues for a continued focus on the family processes of this population.

It is important to note that issues of documentation status are not solely restricted to the undocumented and their children. A recent national survey of almost 1500 Latinx adults indicated that $36 \%$ of them knew someone who had been detained or deported and almost $80 \%$ of them reported feeling an overall anti-immigrant environment in the US (Vargas et al., 2019). This demonstrates the relevance of immigration and documentations status issues for Latinxs in general. Even among native-born and documented Latinx, documentation status conversations could be prompted by news reports or incidents involving family members, friends or others in their community, especially among those living in areas of stricter immigration enforcement (Ayón, 2016). These discussions, however, are much more prevalent, personal, and urgent for those living in mixed-status households. They address crucial matters faced by undocumented Latinx immigrants that extend to their family members, regardless of their documentation status, and are important for understanding how these families socialize their children in reaction to an environment of political adversity that engenders not only fear but isolation from the larger community. Examination of these socialization efforts helps us understand how minority parents experience and consider social inequalities, prejudice and discrimination, as well as how they teach their children to manage them.

\section{Implications for Practice}

Service providers working with undocumented Latinx immigrant families should be mindful of the impact of parents' undocumented status on their children's development and on their ERS (Cross et al., 2020). Assisting parents in devising contingency plans for the care of their children in case of detainment or deportation should be part of the service plan for mixed-status families (Salas et al., 2013). These contingency plans provide both parents and children with the reassuring knowledge that they have prepared for 
unwanted events and future family reunification. Distributing the plans to extended family members or other trusted adults in their community would help avoid the risk of children being left unattended at home or stranded at school in case both parents are detained. In addition, providers could support parents as they undertake the difficult, but necessary, conversations with their children about their vulnerable status. Drawing from a strengths-based approach, these conversations should also emphasize the family's resilience as they navigate this country's sociopolitical climate and provide some strategies to further empower them, especially the children, who are more likely to be documented and less afraid. However, parents must have the final word in deciding when and how documentation status issues are to be discussed with their children (Balderas et al., 2016). Practitioners must also conduct their work with these families through a trauma-informed lens, being aware of the many ways in which migration-related trauma can be expressed as well as watching for other symptoms of loss, family separation and isolation trauma (Lovato et al., 2018).

Furthermore, families impacted by the detainment or deportation of a family member are often thrown into desperate financial crisis. Accordingly, providers should aim to facilitate connections to social services agencies and economic assistance resources. Counseling services in the wake of deportation or raids in their community are also essential as families rebuild and continue moving forward (Suárez-Orozco \& Yoshikawa, 2013). Family separation is a life-changing event that affects the entire undocumented immigrant community, far beyond the family directly impacted. Community organizations should provide spaces for members to meet safely and talk about their fears, issues facing their community, and ways they can mobilize to reduce fears and tensions. Making mental health services available to these families in a variety of different settings (e.g., schools, health clinics, community organizations) would facilitate their access and foster a willingness to utilize these valuable and seriously needed resources to help families cope (Zayas et al., 2017).

Furthermore, practitioners should provide their clients with resources for battling discrimination at the micro and macro levels, ranging from their place of employment, to their children's schools, to their own neighborhood, to governmental agencies. Given the pervasiveness of discrimination experiences among Latinx communities, providers should be aware that this is an issue the parents and children have likely faced and are concerned about. Families should be instructed that they, too, have rights and that talking openly about their plight would promote awareness of the different advocacy resources available to protect both parents and children from discrimination, regardless of their documentation status. Creating awareness of what their rights are during an encounter with immigration agents (at their place of employment, at their home or in their community) would allow these immigrants to protect and defend themselves from ethnic-racial profiling and seek out the necessary support to confront injustices (Ayón, 2016). 


\section{Implications for Research}

In the Integrative Model, parental ERS has been conceptualized as exerting a protective influence on children's development, as it helps mitigate their exposure to risks stemming from their minority status (including those experienced indirectly in family contexts) while simultaneously fostering positive feelings about their ethnic group membership (Hughes et al., 2006). However, the association of documentation status socialization and children outcome is unclear thus far given the dearth of research in the topic. Future studies should explore the documentation status socialization of Latinx parents and the impact of these messages on youth academic and mental health outcomes. In addition, examining these associations longitudinally would provide valuable insights on how these messages might change as children age as well as the relationship between parents' documentation status socialization and the changing sociopolitical climate of this country. Past research has highlighted parents' avoidance of documentation status discussions with younger children based on their desire to shield these youngsters from worrying about family separation until they are older (García, 2019; Cross et al., 2020). Thus, these studies should also aim to tease apart the differential impact of these messages on children of diverse ages.

In addition, future studies should rely on multiple informants taking into account the perspectives of diverse members of the family, including mothers, fathers, youth and extended family yielding greater insight on their socialization practices. Quantitative studies exploring the ERS of Latinx families should rely on ERS measures that are more culturally relevant, such as the one developed by Ayón (2018), which accounts for more dimensions of ERS representing the broader range of experiences of Latinx immigrant families. Lastly, future research exploring documentation status socialization should also focus on the positive coping strategies and adaptations made by immigrant family to diminish the negative impact of the broader sociopolitical environment on their families (Cross et al., 2021). Examining the ERS of these families through a strengths-based lens will allow for a better understanding of how mixed-status communities keep moving forward despite many obstacles imposed by American society and legislation while raising civically minded and engaged children.

\section{Conclusion}

ERS is a fundamental aspect of raising minority children, as parents prepare their children for life beyond the home (Umaña-Taylor et al., 2009). As long as our society continues to marginalize and dehumanize immigrants, a better understanding of the ways in which they adapt and respond to their social context is needed. Thus, incorporating documentation status socialization into the ERS literature will propel the field to broaden its current 
conceptualization of these processes to include the experiences of families of more diverse ethnic and racial groups and those who have varied immigrant and discrimination experiences.

\section{References}

Amuedo-Dorantes, C., \& Arenas-Arroyo, E. (2018). Split families and the future of children: Immigration enforcement and foster care placements. AEA Papers and Proceedings, 108, 368-372. https://doi.org/10.1257/pandp.20181104

Anyiwo, N., Bañales, J., Rowley, S. J., Watkins, D. C., \& Richards Schuster, K. (2018). Sociocultural influences on the sociopolitical development of African American youth. Child Development Perspectives, 12(3), 165-170. https://doi.org/10.1111/cdep.12276

Ayón, C. (2016). Talking to Latino children about race, inequality, and discrimination: Raising families in an anti-immigrant political environment. Journal of the Society for Social Work and Research, 7(3), 449-477. https://dx.doi.org/10.1086/686929

Ayón, C. (2018). Latino immigrant family socialization scale: Development and validation of a multidimensional ethnic-racial socialization measurement. Social Work, 63(3), 222-233. https://dx.doi.org/10.1093/sw/swy016

Ayón, C., \& García, S. J. (2019). Latino immigrant parents' experiences with discrimination: Implications for parenting in a hostile immigration policy context. Journal of Family Issues, 40(6), 805-831. https://doi.org/10.1177/0192513X19827988

Ayón, C., Nieri, T., \& Ruano, E. (2020). Ethnic-racial focialization among Latinx Families: A systematic review of the literature. Social Service Review, 94(4), 693-747.

Ayón, C., Ojeda, I., \& Ruano, E. (2018). Cultural socialization practices among Latino immigrant families within a restrictive immigration socio-political context. Children and Youth Services Review, 88, 57-65. https://doi.org/10.1016/j.childyouth.2018.02.042

Balderas, C. N., Delgado-Romero, E. A., \& Singh, A. A. (2016). Sin papeles: Latino parent-child conversations about undocumented legal status. Journal of Latina/o Psychology, 4(3), 158172. https://doi.org/10.1037/lat0000060

Berkel, C., Knight, G. P., Zeiders, K. H., Tein, J. Y., Roosa, M. W., Gonzales, N. A., \& Saenz, D. (2010). Discrimination and adjustment for Mexican American adolescents: A prospective examination of the benefits of culturally related values. Journal of Research on Adolescence, 20(4), 893-915. https://dx.doi.org/10.1111/j.1532-7795.2010.00668.x

Brabeck, K., \& Sibley, E. (2016). Immigrant parent legal status, parent-child relationships, and child social emotional well-being: A middle childhood perspective. Journal of Child and Family Studies, 25, 1155-1167. https://doi.org/10.1007/s10826-015-0314-4

Brabeck, K., \& Xu, Q. (2010). The impact of detention and deportation on Latino immigrant children and families: A quantitative exploration. Hispanic Journal of Behavioral Sciences, 32(3), 341-361. https://dx.doi.org/10.1177/0739986310374053

Capps, R., Castaneda, R. M., Chaudry, A., \& Santos, R. (2007). Paying the price: The impact of immigration raids on America's children. National Council of La Raza \& The Urban Institute. http://www.urban.org/UploadedPDF/411566_immigration_raids.pdf

Cardoso, B. J., Scott, J. L., Faulkner, M., \& Barros, L. L. (2018). Parenting in the context of deportation risk. Journal of Marriage and Family, 80(2), 301-316. https://doi.org/10.1111/jomf.12463

Chaudry, A., Capps, R., Pedroza, J., Castaneda, R. M., Santos, R., \& Scott, M. M. (2010). Facing our future: Children in the aftermath of immigration enforcement. The Urban Institute. https://www.urban.org/research/publication/facing-our-future

Chavez, L. (2013). The Latino threat: Constructing immigrants, citizens, and the nation. Stanford University Press.

Constante, K., Cross, F. L., Medina, M., \& Rivas-Drake, D. (2019). Ethnic socialization, family cohesion, and ethnic identity development over time among Latinx adolescents. Journal of Youth and Adolescence, 1-12. https://doi.org/10.1007/s10964-019-01139-3 
Cross, F. L., Martinez, S. B., \& Rivas-Drake, D. (2021). Documentation status socialization among Latinx immigrant parents. New Directions for Child and Adolescent Development. https://doi.org/10.1002/cad.20420

Cross, F. L., Agi, A., Montoro, J. P., Medina, M. A., Miller-Tejada, S., Pinetta, B. J., TranDubongco, M., \& Rivas-Drake, D. (2020). Illuminating ethnic-racial socialization among undocumented Latinx parents and its implications for adolescent psychosocial functioning. Developmental Psychology, 56(8), 1458-1474. https://doi.org/10.1037/dev0000826

De Genova, N. (2010) The queer politics of migration: Reflections on "illegality" and incorrigibility. Studies in Social Justice 4(2), 101-126. https://doi.org/10.26522/ssj.v4i2.997

Douglass, S., \& Umaña-Taylor, A. J. (2016). Time-varying effects of family ethnic socialization on ethnic-racial identity development among Latino adolescents. Developmental Psychology, 52(11), 1904-1912. https://doi.org/10.1037/dev0000141

Dreby, J. (2012). The burden of deportation on children in Mexican immigrant families. Journal of Marriage and Family, 74(4), 829-845. https://dx.doi.org/10.1111/j.17413737.2012.00989.x

Espinoza, G., Gonzales, N. A., \& Fuligni, A. J. (2016). Parent discrimination predicts MexicanAmerican adolescent psychological adjustment 1 year later. Child Development, 87(4), 1079-1089. https://doi.org/10.1111/cdev.12521

Finch, B. K., Hummer, R. A., Kol, B., \& Vega, W. A. (2001). The role of discrimination and acculturative stress in the physical health of Mexican-origin adults. Hispanic Journal of Behavioral Sciences, 23(4), 399-429. https://dx.doi.org/10.1177/0739986301234004

FitzGerald, D., McClean, A., \& López, G. (2019). Mexicans in US routinely confront legal abuse, racial profiling, ICE targeting and other civil rights violations. The Conversation. https://theconversation.com/mexicans-in-us-routinely-confront-legal-abuse-racial-profilingice-targeting-and-other-civil-rights-violations-114479

Flippen, C. A., \& Parrado, E. A. (2015). Perceived discrimination among Latino immigrants in new destinations: The case of Durham, North Carolina. Sociological Perspectives, 58(4), 666-685. https://dx.doi.org/10.1177/0731121415574397

García, R. S. (2019). "No vamos a tapar el sol con un dedo": Maternal communication concerning immigration status. Journal of Latinx Psychology, 7(4), 284-303. https://doi.org/10.1037/lat0000131

García Coll, C., Crnic, K., Lamberty, G., Wasik, B. H., Jenkins, R., Garcia, H. V., \& McAdoo, H. P. (1996). An integrative model for the study of developmental competencies in minority children. Child Development, 67(5), 1891-1914. https://dx.doi.org/10.1111/j.14678624.1996.tb01834.x

Gleeson, S., \& Gonzales, R. G. (2012). When do papers matter? An institutional analysis of undocumented life in the United States. International Migration, 50(4), 1-19. https://dx.doi.org/10.1111/j.1468-2435.2011.00726.x

Golash-Boza, T., \& Hondagneu-Sotelo, P. (2013). Latino immigrant men and the deportation crisis: A gendered racial removal program. Latino Studies, 11(3), 271-292. https://doi.org/10.1057/lst.2013.14

Grindal, M., \& Nieri, T. (2015). An examination of ethnic identity and academic performance: Assessing the multidimensional role of parental ethnic-racial socialization among a sample of Latino adolescents. Race and Social Problems, 7(3), 242-255. http://dx.doi.org/10.1007/s12552-015-9154-5

Hall, M. A. (2011). Rethinking safety-net access for the uninsured. New England Journal of Medicine, 364(1), 7-9. https://dx.doi.org/10.1056/NEJMp1011502

Heinrich, C. J. (2018). Presidential address: "A thousand petty fortresses": Administrative burden in US immigration policies and its consequences. Journal of Policy Analysis and Management, 37(2), 211-239. https://dx.doi.org/10.1002/pam.22046

Hughes, D. (2003). Correlates of African American and Latino parents' messages to children about ethnicity and race: A comparative study of racial socialization. American Journal of Community Psychology, 31(1-2), 15-33. https://dx.doi.org/10.1023/A:1023066418688

Hughes, D., Rodriguez, J., Smith, E. P., Johnson, D. J., Stevenson, H. C., \& Spicer, P. (2006). Parents' ethnic-racial socialization practices: A review of research and directions for future 
study. Developmental Psychology, 42(5), 747-770. https://dx.doi.org/10.1037/00121649.42.5.747

Hughes, D., Witherspoon, D., Rivas-Drake, D., \& West-Bey, N. (2009). Received ethnic-racial socialization messages and youths' academic and behavioral outcomes: Examining the mediating role of ethnic identity and self-esteem. Cultural Diversity and Ethnic Minority Psychology, 15(2), 112.

Huguley, J. P., Wang, M. T., Vasquez, A. C., \& Guo, J. (2019). Parental ethnic-racial socialization practices and the construction of children of color's ethnic-racial identity: A research synthesis and meta-analysis. Psychological bulletin, 145(5), 437.

Kulish, A. L., Cavanaugh, A., Stein, G. L., Kiang, L., Gonzalez, L. M., Supple, A. J., \& Mejia, Y. (2019). Ethnic-racial socialization in Latino families: The influence of mothers' socialization practices on adolescent private regard, familism, and perceived ethnic-racial discrimination. Cultural Diversity and Ethnic Minority Psychology, 25(2), 199-209. http://dx.doi.org/10.1037/cdp0000222

Landale, N. S., Hardie, J. H., Oropesa, R. S., \& Hillemeier, M. M. (2015). Behavioral functioning among Mexican-origin children: Does parental legal status matter? Journal of Health and Social Behavior, 56(1), 2-18. https://doi.org/10.1177/0022146514567896

Lovato, K., Lopez, C., Karimli, L., \& Abrams, L. S. (2018). The impact of deportation-related family separations on the well-being of Latinx children and youth: A review of the literature. Children and Youth Services Review, 95, 109-116. https://doi.org/10.1371/journal.pone.0222837

Lykes, M. B., Brabeck, K. M., \& Hunter, C. J. (2013). Exploring parent-child communication in the context of threat: Immigrant families facing detention and deportation in post-9/11 USA. Community, Work \& Family, 16(2), 123-146. https://doi.org/10.1080/13668803.2012.752997.

Massey, D. S., \& Pren, K. A. (2012). Unintended consequences of US immigration policy: Explaining the post-1965 surge from Latin America. Population and Development Review, 38(1), 1-29. https://doi.org/10.1111/j.1728-4457.2012.00470.x

McDermott, E. R., Umaña-Taylor, A. J., \& Martinez-Fuentes, S. (2019). Measuring Latino adolescents' coping with ethnic-racial discrimination. Journal of Psychoeducational Assessment, 37(6), 730-742. https://doi.org/10.1177/0734282918792384

Park, I. J., Du, H., Wang, L., Williams, D. R., \& Alegría, M. (2019). The role of parents' ethnicracial socialization practices in the discrimination-depression link among Mexican-origin adolescents. Journal of Clinical Child \& Adolescent Psychology, 1-14. https://doi.org/10.1080/15374416.2018.1547969

Pinetta, B. J., Blanco Martinez, S., Cross, F. L., \& Rivas-Drake, D. (2020). Inherently political? Associations of parent ethnic-racial socialization and sociopolitical discussions with Latinx youths' emergent civic engagement. American Journal of Community Psychology, 66(1-2), 94-105. https://doi.org/10.1002/ajcp.12435

Rojas-Flores, L., Clements, M. L., Hwang Koo, J., \& London, J. (2017). Trauma and psychological distress in Latino citizen children following parental detention and deportation. Psychological Trauma: Theory, Research, Practice, and Policy, 9(3), 352-361. http://dx.doi.org/10.1037/tra0000177

Salas, L. M., Ayón, C., \& Gurrola, M. (2013). Estamos traumados: The effect of anti immigrant sentiment and policies on the mental health of Mexican immigrant families. Journal of Community Psychology, 41(8), 1005-1020. https://doi.org/10.1002/jcop.21589

Stein, G. L., Gonzales, R. G., García Coll, C., \& Prandoni, J. I. (2016). Latinos in rural, new immigrant destinations: A modification of the Integrative Model of Child Development. In L. J. Crockett \& G. Carlo (Eds.), Rural ethnic minority youth in the United States: Advancing responsible adolescent development (pp. 37-56). Springer. https://link.springer.com/chapter/10.1007/978-3-319-20976-0_3

Suárez-Orozco, C., \& Yoshikawa, H. (2013). Undocumented status: Implications for child development, policy, and ethical research. New Directions for Child and Adolescent Development, (141), 61-78. https://doi.org/10.1002/cad.20043

Suárez-Orozco, C., Yoshikawa, H., Teranishi, R. T., \& Suárez-Orozco, M. M. (2011). Growing up in the shadows: The developmental implications of unauthorized status. Harvard 
Educational Review, 81(3), 438-473.

https://dx.doi.org/10.17763/haer.81.3.g23x203763783m75

Transactional Records Access Clearinghouse. (2016). Historical data: Immigration and customs enforcement removals. https://trac.syr.edu/phptools/immigration/removehistory/

Umaña-Taylor, A. J., Alfaro, E. C., Bámaca, M. Y., \& Guimond, A. B. (2009). The central role of familial ethnic socialization in Latino adolescents' cultural orientation. Journal of Marriage and Family, 71(1), 46-60. https://doi.org/10.1111/j.1741-3737.2008.00579.x

Vargas, E. D., Juárez, M., Sanchez, G. R., \& Livaudais, M. (2019). Latinos' connections to immigrants: How knowing a deportee impacts Latino health. Journal of Ethnic and Migration Studies, 45(15), 2971-2988. https://doi.org/10.1080/1369183X.2018.1447365

Warren, R. (2021). In 2019, the US undocumented population continued a decade-long decline and the foreign-born population neared zero growth. Journal on Migration and Human Security, 9(1), 31-43. https://doi.org/10.1177/2331502421993746

Zayas, L. H. (2015). Forgotten citizens: Deportation, children, and the making of American exiles and orphans. Oxford University Press.

Zayas, L. H., Brabeck, K. M., Heffron, L. C., Dreby, J., Calzada, E. J., Parra-Cardona, J. R., Dettlaff, A. J., Heidbrink, L., Perreira, K. M., \& Yoshikawa, H. (2017). Charting directions for research on immigrant children affected by undocumented status. Hispanic Journal of Behavioral Sciences, 39(4), 412-435. https://doi.org/10.1177/0739986317722971

Zayas, L. H., \& Gulbas, L. E. (2017). Processes of belonging for citizen-children of undocumented Mexican immigrants. Journal of Child and Family Studies, 26(9), 24632474. https://dx.doi.org/10.1007/s10826-017-0755-z 